\title{
Show us your ticks: a survey of ticks infesting dogs and cats across the USA
}

\author{
Meriam N. Saleh * ${ }^{*}$, Kellee D. Sundstrom, Kathryn T. Duncan, Michelle M. lentile, Julia Jordy, Parna Ghosh
} and Susan E. Little

\begin{abstract}
Background: A variety of tick species infest dogs and cats in North America. Although most of these species also readily feed on people, national data regarding the species and abundance of ticks on dogs and cats are lacking. Here we report a large-scale study of ticks from dogs and cats in the USA over a 12-month period.

Methods: Tick submissions were invited from veterinary practices in all 50 states. Ticks were submitted with information about the pet and the attachment sites of each tick marked on a biopsy chart. Upon receipt, ticks were identified to species and stage using morphologic keys; when necessary, species identification was confirmed molecularly.

Results: From February 2018 through January 2019, 10,978 ticks were submitted from 1494 dogs and 336 cats in 49 states and ticks were collected in every month. Dog and cat infestation intensities ranged from 1 to 4765 and from 1 to 38 (median $=1$, mean $=6.7$ and 2.6), respectively. Dogs were primarily infested with Dermacentor variabilis (532/1494; 35.6\%), Ixodes scapularis (409/1494; 27.4\%), Amblyomma americanum (345/1494; 23.1\%) and Rhipicephalus sanguineus (172/1494; 11.5\%). Cats were primarily infested with I. scapularis (156/336; 46.4\%), A. americanum (99/336; $29.5 \%$ ) and D. variabilis (60/336; 17.9\%). Other submitted ticks included A. maculatum, Haemaphysalis longicornis, Otobius megnini, and less common Dermacentor spp. and Ixodes spp. Co-infestations were documented in 93 dogs and 14 cats. Reported attachment sites of common tick species differed. In dogs, A. americanum was most commonly attached to the abdomen, axillary, and inguinal regions; D. variabilis and I. scapularis to the head, neck, and back; and $R$. sanguineus to the head, neck, abdomen, legs, and feet. In cats, I. scapularis was most commonly attached to the head and A. americanum was most commonly attached to the tail and perianal region.
\end{abstract}

Conclusions: These data confirm that dogs and cats in the USA are at risk of tick infestation throughout the year and that tick species present in the region have apparent attachment site preferences.

Keywords: Amblyomma, Attachment site, Cat, Dermacentor, Dog, Ixodidae, Ixodes, Rhipicephalus, Tick

\section{Background}

Ticks are common ectoparasites of significant medical and veterinary importance worldwide. Several different tick species, most of which transmit zoonotic and veterinary pathogens, are known to feed on domestic dogs and cats (Tables 1,2 ). In the USA, common species include Amblyomma americanum, A. maculatum,

*Correspondence: meriam.saleh@okstate.edu

Department of Veterinary Pathobiology, Center for Veterinary Health

Sciences, Oklahoma State University, Stillwater, OK 74078, USA
Dermacentor variabilis, Ixodes scapularis, I. pacificus and Rhipicephalus sanguineus [1], but recent, comprehensive surveys from this region documenting the species and occurrence of ticks on pets and particularly on dogs, are lacking. The close association between people and pets, along with the shared disease risk ticks pose, has fostered recent interest in large-scale surveys of ticks from companion animals $[2,3]$. A review of medical records from 2002- 2004 reported that ticks were found on $29,662 / 2,275,048(1.3 \%)$ dogs in 40 states, but 
Table 1 Representative published reports of ticks recovered from dogs

\begin{tabular}{|c|c|c|c|}
\hline Study population (N; \%) & Ticks identified $\left(n\right.$; tick stages $\left.{ }^{\mathrm{a}}\right)$ & Location & References \\
\hline $\begin{array}{l}\text { Public Health England's passive Tick Surveillance Scheme } \\
\text { (TSS) (1580; nr) }\end{array}$ & $\begin{array}{l}\text { Ixodes ricinus (2104; F/M/N/L) } \\
\text { Ixodes hexagonus (943; F/M/N/L) } \\
\text { Haemaphysalis punctata (164; F/M/L) } \\
\text { Dermacentor reticulatus (47; F/M) } \\
\text { Ixodes canisuga (18; F/N/L) }\end{array}$ & UK & [42] \\
\hline Pet dogs presented to veterinarians $(1383 / 3026 ; 45.7 \%)$ & $\begin{array}{l}\text { Rhipicephalus sanguineus (s.I.) (1822; F/M/N/L) } \\
\text { I. ricinus (468; F/M/N/L) } \\
\text { I. hexagonus (83; F/M/N) } \\
\text { Dermacentor marginatus (5; F/M) } \\
\text { Rhipicephalus bursa (11; F/M/N) } \\
\text { D. reticulatus (7; F/M) } \\
\text { H. punctata (4; F/N) } \\
\text { Ixodes arboricola (32; L) } \\
\text { I. canisuga (4; F/N) } \\
\text { Ixodes gibbosus ( } 2 ; \mathrm{F}) \\
\text { Ixodes festai }(1 ; \mathrm{F})\end{array}$ & Italy & [39] \\
\hline Pet dogs presented to veterinarians (nr) & $\begin{array}{l}\text { I. ricinus }(95 ; \mathrm{A}) \\
\text { R. sanguineus }(\text { s.I.) }(74 ; \mathrm{A}) \\
\text { D. reticulatus }(43 ; \mathrm{A}) \\
\text { I. hexagonus }(12 ; \mathrm{A})\end{array}$ & Belgium, France, Hungary, Italy & [43] \\
\hline Pet dogs presented to veterinarians $(562 ; \mathrm{nr})$ & $\begin{array}{l}\text { R. sanguineus (sensu lato) (1058) } \\
\text { Haemaphysalis longicornis (286) } \\
\text { Rhipicephalus haemaphysaloides (195) } \\
11 \text { too damaged for identification (A/N/L; } \\
\text { species nos. for each stage not specified) }\end{array}$ & China & [44] \\
\hline Pet dogs presented to veterinarians (180; $\mathrm{nr}$ ) & $\begin{array}{l}\text { R. sanguineus (s.l.) (1242) } \\
\text { Amblyomma americanum (36) } \\
\text { Ixodes scapularis (24) } \\
\text { Dermacentor variabilis (10) } \\
\text { Amblyomma maculatum (4) }\end{array}$ & USA (Florida) & [9] \\
\hline $\begin{array}{l}\text { Pet dogs presented to veterinarians and individual sub- } \\
\text { missions }(643 ; n r)\end{array}$ & $\begin{array}{l}\text { R. sanguineus (s.I.) (3069; F/M/N/L) } \\
\text { Ixodes holocyclus (770; F/M/N) } \\
\text { H. longicornis (213; F/N/L) } \\
\text { Ixodes tasmania }(90 ; \mathrm{F} / \mathrm{M} / \mathrm{N} / \mathrm{L}) \\
\text { Ixodes cornuatus }(15 ; \mathrm{F} / \mathrm{N}) \\
\text { Bothriocroton sp. }(14 ; \mathrm{F} / \mathrm{M} / \mathrm{N} / \mathrm{L}) \\
\text { Amblyomma triguttatum triguttatum (10; F/N) } \\
\text { Haemaphysalis bancrofti }(5 ; \mathrm{F} / \mathrm{N}) \\
\text { Ixodes myrmecobii }(4 ; \mathrm{F}) \\
\text { Rhipicephalus australis }(1 ; \mathrm{N})\end{array}$ & Australia & [33] \\
\hline Pet dogs presented to veterinarians (1162; nr) & $\begin{array}{l}\text { H. longicornis (2633; F/M/N/L) } \\
\text { R. sanguineus (s.l.) (882; F/M/N/L) } \\
\text { Haemaphysalis flava (316; F/M/N/L) } \\
\text { Ixodes ovatus (182; F/M/N) } \\
\text { Haemaphysalis hystricis (33; F/M/N) } \\
\text { Haemaphysalis megaspinosa (30; F/N/L) } \\
\text { Ixodes nipponensis (30; F/M/N) } \\
\text { Ixodes persulcatus (27; F/M) } \\
\text { Amblyomma testudinarium (22; F/N/L) } \\
\text { Haemaphysalis campanulata (19; F/M) }\end{array}$ & Japan & [34] \\
\hline
\end{tabular}


Table 1 (continued)

\begin{tabular}{|c|c|c|c|}
\hline Study population (N; \%) & Ticks identified ( $n$; tick stages ${ }^{\mathrm{a}}$ ) & Location & References \\
\hline & Haemaphysalis japonica $(11 ; \mathrm{F} / \mathrm{M} / \mathrm{N})$ & & \\
\hline & Haemaphysalis spp. (17; F/N/L) & & \\
\hline & Ixodes spp. $(2 ; \mathrm{F})$ & & \\
\hline & Haemaphysalis formosensis $(1 ; \mathrm{N})$ & & \\
\hline & Haemaphysalis ias $(1 ; F)$ & & \\
\hline & Unidentified (31; F/M/N/L) & & \\
\hline \multirow{5}{*}{$\begin{array}{l}\text { Pet dogs during rabies vaccination campaign and pet } \\
\text { dogs at selected. Home }(154 / 413 ; 37.3 \%)\end{array}$} & R. sanguineus (s.l.) (674; A/N) & Brazil & {$[45]$} \\
\hline & Amblyomma sp. (146; N/L) & & \\
\hline & Amblyomma cajennense $(6 ; \mathrm{A})$ & & \\
\hline & Amblyomma ovale $(7 ; A)$ & & \\
\hline & Rhipicephalus (Boophilus) microplus (2; N) & & \\
\hline \multirow[t]{9}{*}{ Pet and shelter dogs at selected locations (nr) } & I. scapularis (1147; M/F) & USA (Georgia) & [7] \\
\hline & D. variabilis (628; M/F/N) & & \\
\hline & R. sanguineus (274; F/M/N) & & \\
\hline & A. maculatum (218; F/M/N) & & \\
\hline & A. americanum $(111 ; \mathrm{F} / \mathrm{M} / \mathrm{N})$ & & \\
\hline & Amblyomma tuberculatum $(72 ; \mathrm{L})$ & & \\
\hline & Ixodes affinis (14; M/F) & & \\
\hline & Haemaphysalis leporispalustris $(1 ; \mathrm{F})$ & & \\
\hline & Ixodes cookei $(1 ; \mathrm{F})$ & & \\
\hline \multirow[t]{6}{*}{ Pet dogs at selected homes (870; nr) } & A. americanum (23676; F/M/N/L) & USA (Oklahoma, Arkansas) & [6] \\
\hline & R. sanguineus (46652; F/M/N/L) & & \\
\hline & I. scapularis $(965 ; \mathrm{M} / \mathrm{F})$ & & \\
\hline & D. variabilis (717; M/F) & & \\
\hline & A. maculatum (10; F/M/N) & & \\
\hline & I. cookei $(5 ; \mathrm{F})$ & & \\
\hline
\end{tabular}

a Provided when specified in reference

Abbreviations: F, female; $\mathrm{M}$, male; N, nymph; L, larva; $A$, adult; $N$, number infested; $n$, number of ticks; nr, not reported

information on species or stage was not available [4]. A "citizen-science" survey detailed tick infestations on people and animals across the USA, but did not report which tick species were found on dogs and cats or in the different geographical regions [5].

Several detailed reports of ticks on pets in limited geographical areas of the USA are available (Tables 1,2) [2, $6-14]$, but none are national in scope. Compiling current, comprehensive data about ticks infesting dogs and cats in the USA is time- and resource-intensive but critically important for both veterinary and human health [15]. Improved knowledge of the tick species that pets encounter across the USA can provide valuable information about the geographical distribution of ticks throughout the country and thus the risk posed to humans that share the same environment. Because tick removal was documented at veterinary practices in the present study, we were also able to gain insight into attachment site preferences. The purpose of the present study was to determine the species and stages of ticks infesting dogs and cats throughout the USA and determine tick-host attachment site preferences.

\section{Methods \\ Tick collections}

Ticks submissions were invited from 190 enrolled veterinary practices in all 50 states to ensure broad geographical representation and were supplemented by submissions from other veterinary practices interested in supporting the study. Each practice was provided with instructions and submission kits containing forceps, tick containers, prepaid mailing envelopes and submission forms. Instructions for tick submissions were also made available on a study website [16]. Ticks identified on a dog or cat were removed and placed in a hard-plastic container with a tightly fitting lid which was then sealed in a plastic bag with a completed submission form and shipped to Oklahoma State University; occasionally ticks were submitted in serum tubes or similar hard, tightly sealed containers. The 
Table 2 Representative published reports of ticks recovered from cats

\begin{tabular}{|c|c|c|c|}
\hline Study population $(N ; \%)$ & Ticks identified $\left(n\right.$; tick stages $\left.{ }^{a}\right)$ & Location & References \\
\hline Public Health England's Tick Surveillance Scheme (TSS) (568; nr) & $\begin{array}{l}\text { Ixodes hexagonus }(918 ; \mathrm{F} / \mathrm{M} / \mathrm{N} / \mathrm{L}) \\
\text { Ixodes ricinus }(384 ; \mathrm{F} / \mathrm{M} / \mathrm{N}) \\
\text { Ixodes canisuga }(3 ; \mathrm{F} / \mathrm{N}) \\
\text { Ixodes ventalloi }(3 ; \mathrm{F}) \\
\text { Ixodes frontalis }(1 ; \mathrm{F}) \\
\text { Haemaphysalis punctata }(1 ; \mathrm{F})\end{array}$ & UK & [42] \\
\hline Pet cats presented to veterinarians $(332 ; \mathrm{nr}$ ) & $\begin{array}{l}\text { Ixodes scapularis (423; F/M/N/L) } \\
\text { Amblyomma americanum (226; F/M/N/L) } \\
\text { Dermacentor variabilis (131; F/M/N) } \\
\text { Ixodes pacificus (11) } \\
\text { Ixodes banksi (1) } \\
\text { Dermacentor occidentalis (1) } \\
\text { Amblyomma maculatum (1) } \\
\text { Otobius megnini (1) } \\
\text { Rhipicephalus sanguineus (s.l.) (1) }\end{array}$ & USA & {$[2]$} \\
\hline Pet cats presented to veterinarians (nr) & $\begin{array}{l}\text { I. ricinus (152; A) } \\
\text { R. sanguineus (s.l.) (42; A) } \\
\text { Dermacentor reticulatus (16; A) } \\
\text { I. hexagonus }(14 ; \mathrm{A} / \mathrm{N})\end{array}$ & $\begin{array}{l}\text { Germany, France, } \\
\text { Hungary and Italy }\end{array}$ & [43] \\
\hline Pet cats presented to veterinarians and individual submissions (152; $\mathrm{nr}$ ) & $\begin{array}{l}\text { Ixodes holocyclus }(185 ; \mathrm{F} / \mathrm{M} / \mathrm{N}) \\
\text { Ixodes tasmania }(39 ; \mathrm{F} / \mathrm{N} / \mathrm{L}) \\
\text { Haemaphysalis bancrofti }(1 ; \mathrm{F}) \\
\text { Ixodes cornuatus }(1 ; \mathrm{F}) \\
\text { Ixodes hirsti }(1 ; \mathrm{F}) \\
\text { Ixodes myrmecobii }(1 ; \mathrm{F}) \\
\text { R. sanguineus }(\mathrm{s} . \mathrm{I})(1 ; \mathrm{F})\end{array}$ & Australia & [33] \\
\hline $\begin{array}{l}\text { Pet cats presented to veterinarians and free-roaming cats presented to } \\
\text { spay/neuter program }(37 / 308 ; 12 \%)\end{array}$ & $\begin{array}{l}\text { I. ventalloi (62; F/M) } \\
\text { I. ricinus (20; F/M) } \\
\text { Ixodes spp. }(5 ; \mathrm{F}) \\
\text { R. sanguineus (s.I.) (28; F/M) } \\
\text { Rhipicephalus pusillus (17; M) }\end{array}$ & Italy (Sicily, Calabria) & [46] \\
\hline Pet cats presented to veterinarians $(136 ; \mathrm{nr})$ & $\begin{array}{l}\text { Haemaphysalis longicornis (106; F/M/N/L) } \\
\text { Amblyomma testudinarium (80; F/N/L) } \\
\text { Ixodes ovatus }(55 ; \mathrm{F} / \mathrm{M} / \mathrm{N}) \\
\text { Haemaphysalis flava }(18 ; \mathrm{F} / \mathrm{N} / \mathrm{L}) \\
\text { Haemaphysalis hystricis }(12 ; \mathrm{N}) \\
\text { Ixodes nipponensis }(10 ; \mathrm{F} / \mathrm{N}) \\
\text { Ixodes persulcatus }(6 ; \mathrm{F}) \\
\text { Haemaphysalis japonica }(2 ; \mathrm{N}) \\
\text { R. sanguineus (s.l.) (2; F) } \\
\text { Haemaphysalis megaspinosa (1; L) } \\
\text { Ixodes granulatus (1; F) }\end{array}$ & Japan & [34] \\
\hline
\end{tabular}

a Provided when specified in reference

Abbreviations: F, female; M, male; N, nymph; L, larva; A, adult; N, number infested; n, number of ticks; nr, not reported

submission form collected information on removal date of tick; age, weight, sex, spay/neuter status and breed of pet; owner reported estimate of percent time the pet spent outside; and a diagram to indicate the tick attachment location(s) on the dog or cat. When multiple ticks were present we requested that all ticks be collected and submitted. 


\section{Tick identification}

Ticks were immediately examined upon receipt, the stage (female, male, nymph, larva) of each tick recorded and tick genus and species determined using standard keys [17-23]. After identification, specimens were held in $70 \%$ ethanol at $-20{ }^{\circ} \mathrm{C}$. An e-mail was sent to the submitting veterinarian with the initial morphologic identification and a list of pathogens that species/ stage is known to transmit, if any. When damage to the specimen precluded identification by morphology, or if the species identification was unusual or uncertain due to morphologic similarity between congeners, ticks were bisected to retain anterior morphologic features and nucleic acid extracted from the posterior half with a commercial kit (Illustra GenomicPrep Kit, GE Healthcare, Marlborough, MA, USA) for molecular identification. Briefly, PCR amplification and direct sequencing of a $16 S$ rRNA gene fragment [24, 25] was utilized for Ixodes, Haemaphysalis and Amblyomma, a cox1 gene fragment [26] was also utilized for Ixodes and Haemaphysalis and an ITS2 gene fragment [27] was used for Dermacentor. Amplicons were visualized in GelRed-stained (Biotium, Inc., Freemont, CA, USA) agarose gels to confirm expected size and purified using a commercial kit according to manufacturer's instructions (Wizard ${ }^{\circledR}$ SV Gel and PCR Clean-Up System, Promega, Madison, WI, USA). Sequence analysis and alignment were performed using MacVector software (MacVector, Inc., Cary, NC, USA) and were compared with available sequences using the nucleotide Basic Local Alignment Search Tool (BLASTn, National Center for Biotechnology Information, Bethesda, MD, USA). Sequence identity was confirmed via visual inspection of the chromatogram and identity to available sequences. Anterior halves of bisected ticks were retained in $70 \%$ ethanol at $-20^{\circ} \mathrm{C}$.

\section{Data management and quality assurance}

Tick identification including number of ticks submitted, species and stage was recorded in a log along with the patient information. All data were entered into spreadsheets (Microsoft Excel version 16.16.8). Prior to summary and statistical analyses, quality assurance was performed by reviewing both individual identifications and data entry. Attachment site data were recorded from marked biopsy charts on original submission cards. Regions of the body were divided into 5 areas for analysis: head, ears and neck; abdomen, axillary and inguinal; legs and feet; back; and tail and perianal region. Attachment site was only assessed for dogs and cats infested with a single species of adult tick.

\section{Statistical analyses}

Statistical analyses were performed using JMP (Version 12. SAS Institute Inc., Cary, NC, 1989-2019). Confidence intervals (CI 95\%) were calculated for average reported weight and age. Chi-square tests, with significance levels below $\alpha=0.05$, were performed to evaluate differences in sex and altered status of dogs and cats with ticks compared to that reported from the general pet population in the USA and to evaluate differences in tick attachment site on dogs and cats among the most common tick species received. Percent ranked quintiles were established for tick attachment site data to depict attachment site preferences graphically.

\section{Results \\ Dogs with ticks}

A total of 263 veterinary practices in 49 states (all but North Dakota, USA) submitted 10,087 ticks from 1494 dogs (Table 3). Practices that submitted ticks were located in the Northeast $(n=42)$, South $(n=100)$, Midwest $(n=96)$ and West $(n=25)$. An average of 6.7 ticks (median 1) were submitted from each dog and infestation intensity ranged between $1-4765$, with 82 (5.5\%) dogs infested with 10 or more ticks. Reported weight of dogs with ticks varied from 0.16 to $90.7 \mathrm{~kg}$ (mean $20.1 \mathrm{~kg}$; 95\% CI: $19.5-20.8 \mathrm{~kg}$ ) and reported age ranged from 40 days to 19 years (mean 4.8 years; $95 \%$ CI: $4.5-8.2$ years). Estimated percent time outside as reported by owner was categorized as $<1 \%$ (7/1042; 0.7\%), 1-30\% (509/1042; $48.8 \%), 31-70 \%$ (290/1042; $27.8 \%)$ and $>70 \%$ (236/1042; 22.6\%); for 452 dogs, an estimate of time spent outside was not provided. Of the dogs for which sex and altered status were provided 719/1438 (50.0\%) were male and $720 / 1438$ (50.0\%) were female, which is not significantly different than the estimates of males and females for the general pet population of $\operatorname{dogs}\left(\chi^{2}=1.970, d f=1\right.$, $P=0.1595$ ) [28]; 441/718 (61.4\%) of males were neutered, which is not significantly different than the estimates for the general pet population of dogs $\left(x^{2}=0.02, d f=1\right.$, $P=0.9690)$ [28] and 454/719 (63.1\%) of females were spayed which is significantly different than the estimates for the general population where $67.4 \%$ of females were spayed $\left(x^{2}=6.02, d f=1, P=0.0142\right)$ [28].

Of the 1494 dogs with ticks, $D$. variabilis was present on $35.6 \%$ (532/1494), Ixodes scapularis on $27.4 \%$ (409/1494), A. americanum on $23.1 \%(345 / 1494)$ and $R$. sanguineus on $11.4 \%(174 / 1494)$. A smaller number of dogs were infested with $A$. maculatum (98/1494; 6.6\%), I. pacificus (22/1494; $1.5 \%)$, or Otobius megnini (6/1494; 0.4\%). A few dogs were found to be infested with $I$. angustus $(n=5), I$. cookei $(n=4)$, I. affinis $(n=4)$, Ixodes sp. $(n=1)$, D. albipictus $(n=2)$, or $D$. andersoni $(n=1)$. Co-infestations with more than one tick species were documented on 93 dogs. 
Table 3 Ticks collected from domestic dogs in the USA by species, stage and month of collection

\begin{tabular}{|c|c|c|c|c|c|c|c|c|c|c|c|c|c|c|}
\hline Species & Stage & Total & Jan & Feb & Mar & Apr & May & Jun & Jul & Aug & Sep & Oct & Nov & Dec \\
\hline \multirow{4}{*}{ Rhipicephalus sanguineus } & $F$ & 486 & 14 & 0 & 13 & 23 & 24 & 65 & 209 & 96 & 17 & 13 & 11 & 1 \\
\hline & $M$ & 617 & 45 & 0 & 27 & 30 & 29 & 65 & 227 & 160 & 12 & 20 & 2 & 0 \\
\hline & $N$ & 1120 & 0 & 0 & 0 & 1 & 0 & 40 & 1016 & 30 & 32 & 1 & 0 & 0 \\
\hline & $L$ & 4029 & 0 & 0 & 0 & 0 & 0 & 5 & 4005 & 19 & 0 & 0 & 0 & 0 \\
\hline \multirow[t]{4}{*}{ Amblyomma americanum } & $\mathrm{F}$ & 514 & 0 & 0 & 12 & 54 & 163 & 172 & 35 & 69 & 8 & 0 & 0 & 1 \\
\hline & M & 292 & 4 & 0 & 14 & 50 & 90 & 102 & 17 & 11 & 4 & 0 & 0 & 0 \\
\hline & $\mathrm{N}$ & 363 & 0 & 0 & 2 & 12 & 44 & 129 & 47 & 75 & 53 & 1 & 0 & 0 \\
\hline & $L$ & 762 & 4 & 0 & 0 & 0 & 1 & 0 & 242 & 84 & 418 & 13 & 0 & 0 \\
\hline \multirow[t]{4}{*}{ Dermacentor variabilis } & $\mathrm{F}$ & 631 & 0 & 0 & 0 & 21 & 198 & 172 & 142 & 46 & 45 & 4 & 3 & 0 \\
\hline & M & 392 & 0 & 0 & 0 & 25 & 128 & 105 & 74 & 20 & 36 & 3 & 1 & 0 \\
\hline & $\mathrm{N}$ & 2 & 0 & 0 & 0 & 0 & 0 & 1 & 1 & 0 & 0 & 0 & 0 & 0 \\
\hline & $L$ & 0 & 0 & 0 & 0 & 0 & 0 & 0 & 0 & 0 & 0 & 0 & 0 & 0 \\
\hline \multirow[t]{4}{*}{ Ixodes scapularis } & $\mathrm{F}$ & 489 & 37 & 6 & 8 & 34 & 34 & 14 & 5 & 0 & 4 & 158 & 151 & 38 \\
\hline & M & 84 & 6 & 3 & 2 & 1 & 2 & 0 & 0 & 0 & 1 & 37 & 21 & 11 \\
\hline & $\mathrm{N}$ & 3 & 0 & 0 & 0 & 0 & 0 & 1 & 0 & 1 & 0 & 1 & 0 & 0 \\
\hline & $L$ & 0 & 0 & 0 & 0 & 0 & 0 & 0 & 0 & 0 & 0 & 0 & 0 & 0 \\
\hline \multirow[t]{4}{*}{ Other } & $\mathrm{F}$ & 128 & 7 & 13 & 6 & 2 & 4 & 6 & 17 & 31 & 21 & 5 & 12 & 4 \\
\hline & M & 118 & 2 & 1 & 0 & 4 & 3 & 11 & 19 & 41 & 29 & 5 & 3 & 0 \\
\hline & $N$ & 53 & 0 & 0 & 26 & 0 & 1 & 0 & 1 & 10 & 3 & 11 & 0 & 1 \\
\hline & $L$ & 4 & 0 & 0 & 0 & 0 & 0 & 0 & 0 & 4 & 0 & 0 & 0 & 0 \\
\hline Total & & 10,087 & 119 & 23 & 110 & 257 & 721 & 888 & 6057 & 697 & 683 & 272 & 204 & 56 \\
\hline
\end{tabular}

Note: Other submitted ticks included A. maculatum, I. pacificus, O. megnini, I. affinis, I. cookei, I. angustus, Ixodes sp., H. longicornis, D. albipictus and D. andersoni Abbreviations: $\mathrm{F}$, female; $\mathrm{M}$, male; $\mathrm{N}$, nymph; L, larva

Table 4 Ticks collected from domestic cats in the USA by species, stage and month of collection

\begin{tabular}{|c|c|c|c|c|c|c|c|c|c|c|c|c|c|c|}
\hline Species & Stage & Total & Jan & Feb & Mar & Apr & May & Jun & Jul & Aug & Sep & Oct & Nov & Dec \\
\hline \multirow[t]{4}{*}{ Amblyomma americanum } & $\mathrm{F}$ & 93 & 0 & 0 & 2 & 6 & 45 & 33 & 6 & 0 & 1 & 0 & 0 & 0 \\
\hline & M & 32 & 0 & 0 & 1 & 2 & 15 & 11 & 0 & 1 & 1 & 0 & 1 & 0 \\
\hline & N & 92 & 0 & 0 & 2 & 9 & 27 & 20 & 5 & 22 & 6 & 1 & 0 & 0 \\
\hline & L & 126 & 0 & 0 & 0 & 0 & 0 & 7 & 27 & 41 & 39 & 12 & 0 & 0 \\
\hline \multirow[t]{4}{*}{ Dermacentor variabilis } & $F$ & 48 & 0 & 0 & 1 & 1 & 20 & 13 & 7 & 1 & 1 & 0 & 4 & 0 \\
\hline & M & 41 & 0 & 0 & 0 & 4 & 13 & 7 & 8 & 1 & 0 & 0 & 8 & 0 \\
\hline & $\mathrm{N}$ & 1 & 0 & 0 & 0 & 0 & 0 & 0 & 0 & 1 & 0 & 0 & 0 & 0 \\
\hline & L & 0 & 0 & 0 & 0 & 0 & 0 & 0 & 0 & 0 & 32 & 0 & 0 & 0 \\
\hline \multirow[t]{4}{*}{ Ixodes scapularis } & $\mathrm{F}$ & 225 & 8 & 0 & 4 & 2 & 12 & 4 & 1 & 0 & 3 & 110 & 53 & 28 \\
\hline & M & 41 & 2 & 0 & 0 & 0 & 1 & 2 & 0 & 0 & 0 & 28 & 5 & 3 \\
\hline & $N$ & 19 & 0 & 0 & 0 & 1 & 7 & 8 & 1 & 0 & 2 & 0 & 0 & 0 \\
\hline & L & 2 & 0 & 0 & 0 & 0 & 0 & 2 & 0 & 0 & 0 & 0 & 0 & 0 \\
\hline \multirow[t]{4}{*}{ Other } & $\mathrm{F}$ & 20 & 0 & 2 & 0 & 0 & 1 & 5 & 8 & 2 & 1 & 0 & 1 & 0 \\
\hline & M & 4 & 1 & 0 & 0 & 0 & 0 & 0 & 3 & 0 & 0 & 0 & 0 & 0 \\
\hline & $\mathrm{N}$ & 115 & 22 & 0 & 0 & 0 & 0 & 9 & 3 & 29 & 18 & 13 & 4 & 17 \\
\hline & L & 32 & 0 & 0 & 0 & 0 & 0 & 0 & 0 & 0 & 0 & 0 & 0 & 0 \\
\hline Total & & 891 & 33 & 2 & 10 & 25 & 141 & 121 & 69 & 98 & 104 & 164 & 76 & 48 \\
\hline
\end{tabular}




\section{Cats with ticks}

A total of 109 veterinary practices in 39 states submitted 891 ticks from 336 cats (Table 4). These practices were located in the Northeast $(n=25)$, South $(n=40)$, Midwest $(n=30)$ and West $(n=14)$. An average of 2.6 ticks (median 1) were submitted from each cat and infestation intensity ranged from 1 to 38, with $16(4.8 \%)$ cats infested by 10 or more ticks. Reported weight of cats with ticks varied from 0.18 to $13.5 \mathrm{~kg}$ (mean $4.4 \mathrm{~kg}$; 95\% CI: 3.9$8.6 \mathrm{~kg}$ ) and reported age ranged from 18 days to 18 years (mean 4.4 years; 95\% CI: 3.9-8.6 years). Estimated percent time outside as reported by owner was categorized as none $(12 / 283 ; 4.2 \%), 0.5-30 \%(36 / 283 ; 12.7 \%), 31-70 \%$ $(75 / 283 ; 26.5 \%)$ and $>70 \%(160 / 283 ; 56.5 \%)$; for 53 cats an estimate of time spent outside was not provided. Of the cats for which sex and altered status were provided $194 / 331$ (58.6\%) were male and 137/331 (41.4\%) were female; $130 / 194$ (67.0\%) of males were neutered and $90 / 137(65.7 \%)$ of females were spayed which is significantly different than the estimates for the general pet population of cats where only $49.6 \%$ of pet cats were male and $50.4 \%$ were female $\left(\chi^{2}=10.60, d f=1, P=0.0011\right)$; and $83 \%$ of males and $81 \%$ of females were altered $\left(\chi^{2}=36.87\right.$, $\left.d f=1, P<0.0001 ; \chi^{2}=22.34, d f=1, P<0.0001\right)$ [28].

Of the 336 cats with ticks, I. scapularis was present on $46.4 \%$ (156/336), A. americanum on $29.5 \%$ (99/336) and $D$. variabilis on $17.6 \%(59 / 336)$. A smaller number of cats were infested with O. megnini (13/336; 3.9\%), $R$. sanguineus (5/336; 1.5\%), A. maculatum (5/336; $1.5 \%)$, or D. albipictus $(4 / 336 ; 1.2 \%)$. A few cats were found to be infested with I. pacificus $(n=3), I$. affinis $(n=3)$, I. angustus $(n=1), I$. cookei $(n=1), D$. andersoni $(n=2)$, or $H$. longicornis $(n=1)$. Co-infestations with more than one tick species were documented on 14 cats.

\section{Tick species and stages identified}

In dogs, 14 tick species were identified (Table 3 ). The majority of ticks submitted from dogs were $R$. sanguineus (sensu lato) (6252/10,087; 62.0\%), A. americanum
(1931/10,087; 19.1\%), D. variabilis (1025/10,087; 10.2\%) and I. scapularis $(576 / 10,087 ; 5.7 \%)$ (Table 3$)$. A number of other tick species were submitted including $A$. maculatum $(n=188)$, O. megnini $(n=35)$, I. pacificus $(n=34)$, I. affinis $(n=16)$, I. cookei $(n=15)$, I. angustus $(n=5)$, Ixodes sp. $(n=4), H$. longicornis $(n=3), D$. albipictus $(n=2)$ and $D$. andersoni $(n=1)$.

In cats, 13 tick species were identified (Table 4). The majority of ticks submitted were A. americanum (343/891; 38.5\%), I. scapularis $(287 / 891 ; 32.2 \%)$ and $D$. variabilis $(122 / 891 ; 13.7 \%)$ (Table 4$)$. Other submitted tick species included O. megnini $(n=74)$, A. maculatum $(n=32)$, I. cookei $(n=32), R$. sanguineus (sensu lato) $(n=14), D$. albipictus $(n=6)$, I. affinis $(n=5)$, I. pacificus $(n=3), H$. longicornis $(n=2), D$. andersoni $(n=2)$ and $I$. angustus $(n=1)$. The majority of submitted ticks were larvae $(4985 / 10,978 ; 45.4 \%)$, followed by adult females $2635 / 10,978 ; 24.0 \%)$, nymphs $(1737 / 10,978 ; 15.8 \%)$ and adult males $(1621 / 10,978 ; 14.8 \%)$. Adult females were the predominant stage of $D$. variabilis $(679 / / 1115 ; 60.9 \%)$ and I. scapularis (714/863; 82.7\%) submitted, while larvae were the majority of $R$. sanguineus (4029/6266; 64.3\%) and $A$. americanum $(888 / 2274 ; 39.1 \%)$ submitted. Ticks were submitted in every month of the year, with the highest number of ticks recovered in July (6126/10,978; 55.8\%) and primarily consisting of $R$. sanguineus (5467/6126; 89.2\%) (Tables 3, 4).

\section{Site of tick attachment}

Attachment site data from single-species and singlestage infestations of adult ticks were available for 169 dogs with $A$. americanum, 317 dogs with I. scapularis, 386 dogs with $D$. variabilis and 92 dogs with $R$. sanguineus. Reported tick attachment sites are summarized in Table 5 and Fig. 1. Amblyomma americanum was more commonly attached ventrally $\left(x^{2}=27.6, d f=1\right.$, $P<0.0001) ; D$. variabilis, I. scapularis and $R$. sanguineus were more commonly attached dorsally $\left(\chi^{2}=43.1, d f=1\right.$, $P<0.0001 ; X^{2}=104.0, d f=1, P<0.0001 ; \chi^{2}=6.4, d f=1$,

Table 5 Number (percent) of adult ticks attached to different sites on dogs

\begin{tabular}{|c|c|c|c|c|}
\hline Attachment site & Amblyomma americanum & Dermacentor variabilis & Ixodes scapularis & $\begin{array}{l}\text { Rhipicephalus } \\
\text { sanguineus }\end{array}$ \\
\hline Ventral & $156(67.2)^{*}$ & $192(35.8)$ & $107(25.2)$ & $136(42.9)$ \\
\hline Dorsal & $76(32.8)$ & $344(64.2)^{*}$ & $317(74.8)^{*}$ & $181(57.1)^{*}$ \\
\hline Head, ears and neck & $66(28.4)$ & $328(61.2)^{*}$ & $287(67.7)^{*}$ & $140(44.2)^{*}$ \\
\hline Abdomen, axillary, inguinal & $92(39.7)^{*}$ & $64(11.9)$ & $41(9.7)$ & $77(24.3)^{*}$ \\
\hline Legs and feet & $28(12.1)$ & $37(6.9)$ & $17(4.0)$ & $53(16.7)^{*}$ \\
\hline Back & $28(12.1)$ & $97(18.1)^{*}$ & $77(18.2)^{*}$ & $25(7.9)$ \\
\hline Tail and perianal & $18(7.8)$ & $10(1.9)$ & $2(0.5)$ & $22(6.9)$ \\
\hline Total & 232 & 536 & 424 & 317 \\
\hline
\end{tabular}

*Indicates a significant difference at $a=0.05$ 


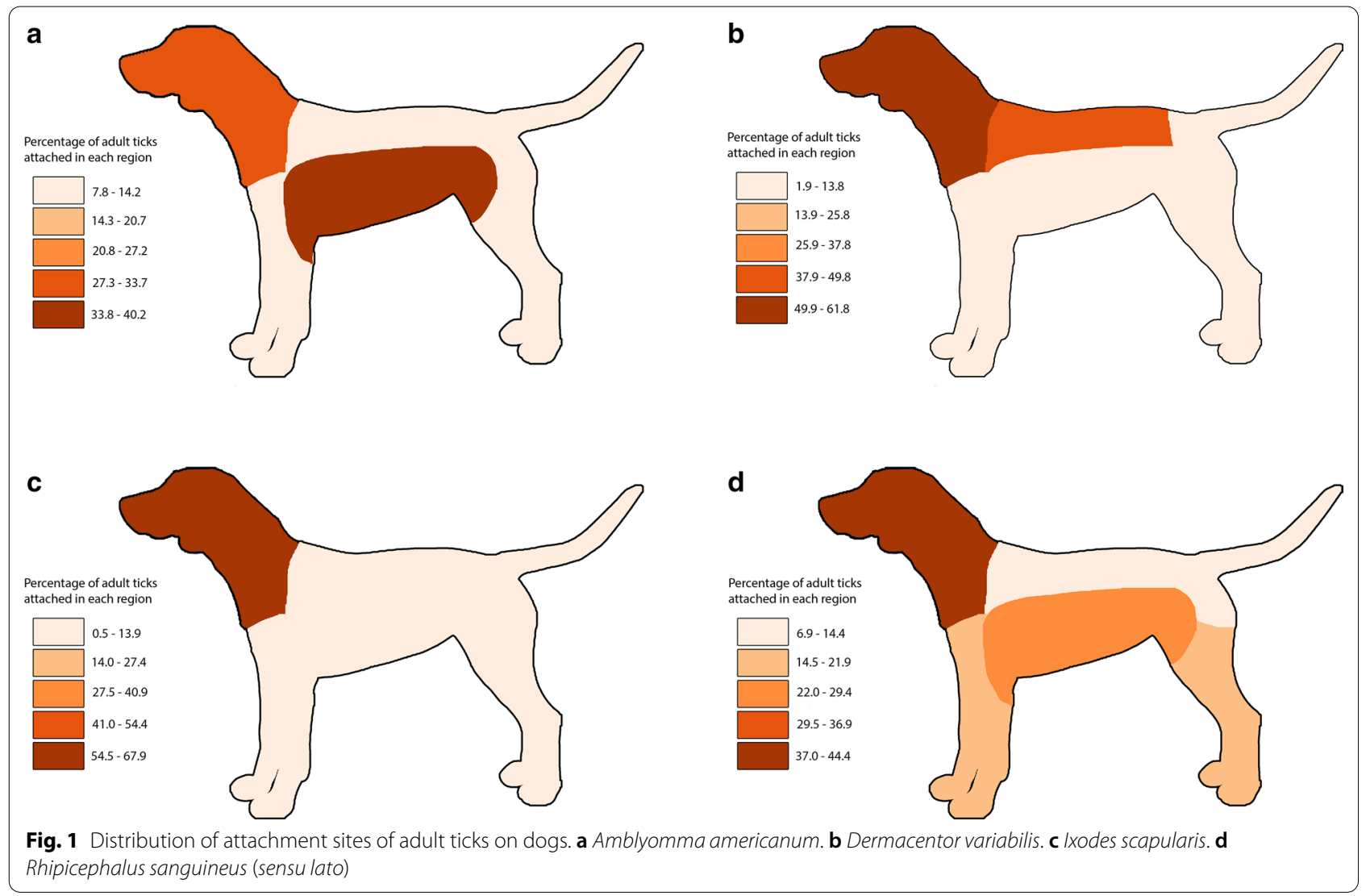

$P=0.0115$, respectively). Amblyomma americanum was more commonly attached to the abdomen, axillary and inguinal region $\left(x^{2}=85.25, d f=1, P<0.0001\right)$; Dermacentor variabilis and Ixodes scapularis were more commonly attached to the head, ears and neck $\left(X^{2}=15.43\right.$, $d f=1, P=0.0008 ; X^{2}=41.93, d f=1, P<0.0001$, respectively) and also to the back $\left(\chi^{2}=14.64, d f=1, P=0.0001\right.$; $X^{2}=4.48, d f=1, P=0.0342$, respectively). Rhipicephalus sanguineus was more commonly attached to the head, ears and neck $\left(\chi^{2}=16.97, d f=1, P=0.00004\right)$, abdomen, axillary and inguinal regions $\left(\chi^{2}=10.15, d f=1\right.$, $P=0.0014)$, as well as the legs and feet $\left(\chi^{2}=29.76, d f=1\right.$, $P<0.0001$ ).

Attachment site data from single-species infestations were available for 33 cats with $A$. americanum, 116 cats with $I$. scapularis and 37 cats with $D$. variabilis. Reported tick attachment sites are summarized in Table 6 and Figure 2. Amblyomma americanum was more commonly attached ventrally $\left(\chi^{2}=12.6, d f=1\right.$, $P=0.0004) ; D$. variabilis and $I$. scapularis were more

Table 6 Number (percent) of adult ticks attached to different sites on cats

\begin{tabular}{llll}
\hline Attachment site & Amblyomma americanum & Dermacentor variabilis & Ixodes scapularis \\
\hline Ventral & $45(72.6)^{*}$ & $16(30.8)$ & $62(35.4)$ \\
Dorsal & $17(27.4)$ & $36(69.2)^{*}$ & $113(64.6)^{*}$ \\
Head, ears and neck & $3(4.8)$ & $29(55.8)$ & $151(86.3)^{*}$ \\
Abdomen, axillary, inguinal & $13(21.0)$ & $3(5.8)$ & $2(1.1)$ \\
Legs and feet & $5(8.1)$ & $2(3.8)$ & $4(2.3)$ \\
Back & $9(14.5)$ & $17(32.7)$ & $17(9.7)$ \\
Tail and perianal & $32(51.6)^{*}$ & $1(1.9)$ & $1(0.6)$ \\
Total & 62 & 52 & 175 \\
\hline
\end{tabular}

*Indicates a significant difference at $a=0.05$ 


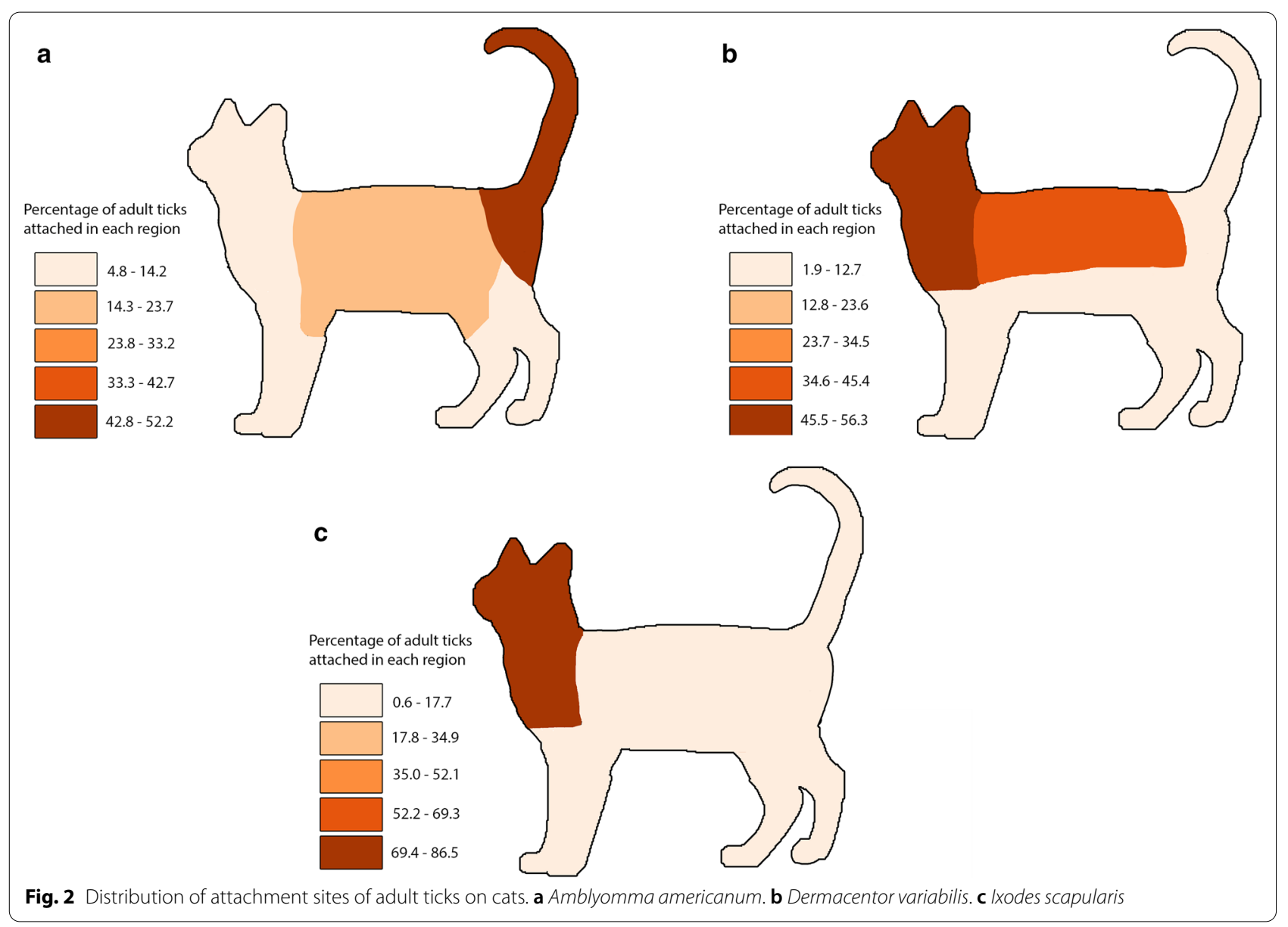

commonly attached dorsally $\left(\chi^{2}=7.7, d f=1, P=0.0055\right.$; $\left.X^{2}=14.9, d f=1, P=0.0001\right)$. Amblyomma americanum was most commonly attached to the tail and perianal region $\left(x^{2}=120.74, d f=1, P<0.0001\right)$ and $I$. scapularis to the head, ears and neck $\left(\chi^{2}=100.73, d f=1, P<0.0001\right) ; D$. variabilis did not have a statistically significant reported area of attachment $\left(\chi^{2}=1.55, d f=1, P=0.21\right)$.

\section{Discussion}

Our data confirm that tick infestations on dogs and cats in the USA are widespread. In the present study, ticks were identified from pets from a larger geographical area than has been reported in the USA [2, 4-14]. The primary tick species identified ( $R$. sanguineus, A. americanum, D. variabilis and I. scapularis) constituted more than $95 \%$ of the ticks submitted from dogs, as was seen in earlier regional reports [6, 9]. Similarly, more than $80 \%$ of the ticks found on cats were A. americanum, I. scapularis, or D. variabilis, as has been described in previous surveys [2, 8-10]. Most pets with ticks had outdoor access, but a variety of tick species were submitted from a few dogs and cats that were reported to rarely or never go outside, suggesting ticks carried into the home on clothing or other pets may create a risk to indoor pets [2].

Less common tick species were also submitted from dogs and cats in the present study. Gulf Coast ticks, $A$. maculatum, were submitted from 98 dogs and 5 cats and have been previously reported from pets, but the geographical distribution appears to be expanding $[6,7,9$, 29]. Nymphs of $O$. megnini were submitted from the ear canals of 6 dogs and 13 cats. Although relatively uncommon, some spinose ear tick infestations in the present study were intense, with 26 nymphs from a single dog and 16 nymphs from a single cat, supporting the assertion that clinically relevant infestations with $O$. megnini occur in dogs and cats $[1,30,31]$. The Asian longhorned tick, $H$. longicornis, a species recently recognized in the USA [32], was submitted from 2 dogs and 1 cat. Longhorned ticks are commonly found on dogs and cats in other areas of the world where the species has long been present [33-35] and we expect to continue to identify this tick from pets in the USA in the future. 
The present study also confirmed that immature stages of some common tick species readily infest dogs and cats. Larvae and nymphs constituted the majority of $A$. americanum and $R$. sanguineus submissions from dogs, corroborating on a national scale findings from a large, regional survey of ticks infesting dogs [6]. A majority of the $A$. americanum submitted from cats in the present study were also larvae or nymphs, an observation that has been described in earlier reports [2, 8]. Two cats harbored nymphs of $R$. sanguineus (sensu lato), a finding not previously reported in North America; adults of this species have been identified from cats in the USA and nymphs are reported from cats from other areas of the world [2, $9,36]$. Immature tick stages are important for pet health and may be overlooked due to their small size, an issue that can contribute to failing to recognize the complete tick risk faced by pets $[2,8,9]$.

Host attachment site preferences also were evident among adult ticks in the present study. Adult A. americanum were more commonly attached ventrally and adult $D$. variabilis, $R$. sanguineus and $I$. scapularis were more commonly attached dorsally, as has been previously noted $[2,6]$. In dogs in the present study, D. variabilis and $I$. scapularis were found more commonly attached to the head, ears, neck and back. In a survey of ticks removed from dogs in Europe, I. ricinus and I. hexagonus preferred the head and $D$. reticulatus the back $[37,38]$. In dogs in the present study, R. sanguineus was more commonly attached to the head, ears and neck, as well as the legs and feet. This finding agrees with earlier reports in both the USA and Europe, where R. sanguineus was commonly found attached between the toes [6,39].

Limitations with the present study include sample bias, incomplete data from all pets with ticks and the broad geography from which ticks were submitted. Even when outdoor access was indicated, we do not have precise habitat information for each pet. Cats also appear to be under-represented as hosts for ticks. Estimates suggest that cats outnumber dogs as pets in the USA [40], but less than $20 \%$ of submissions were from cats. However, we relied on ticks collected from veterinary visits and cats are not taken to the veterinarian as often as dogs [41]. Complete data on factors such as attachment site were not provided for every submission and attachment sites from co-infestations with multiple species or stages were not included in the analysis as the original location of each tick on the pet could not be determined. Omitting these co-infested pets from the attachment site analysis was necessary but limited the power of our results. Finally, phenology of ticks varies with geography, precluding complete analysis of seasonality in the present paper.

\section{Conclusions}

This study revealed that a diverse array of ticks infest dogs and cats across the USA and throughout the year. Attachment site predilections were also confirmed, targeting key anatomic areas to examine when attempting to evaluate pets for active tick-infestation. This study also highlights the importance of broad-spectrum tick control in pets. Given the continued increase and geographical spread of tick populations in the USA [29] routine use of tick control is increasingly important for protecting pets from ticks. Surveillance of pets for ticks provides a valuable resource for understanding the tick risk faced by dogs, cats and people.

\section{Abbreviations \\ PCR: polymerase chain reaction; 16S rRNA: 165 ribosomal RNA gene; cox1: cytochrome c oxidase subunit 1; ITS2: internal transcribed spacer 2.}

\section{Acknowledgements}

We are grateful to the many veterinarians and veterinary technicians who took time out of their already busy schedules to collect ticks from dogs and cats, complete forms and send both to us for use in this study. The dedication of the veterinary profession to understanding tick and tick-borne infection risk in our patients is inspiring and greatly appreciated.

\section{Authors' contributions}

SL conceived of and designed the study. MS developed the overall workflow and served as the main contact and lead investigator. SL, MS, KS, KD, MI, JJ and PG identified ticks using morphological and molecular techniques. MS and SL performed the statistical analyses and drafted the manuscript. All authors read and approved the final manuscript.

\section{Funding}

Funding to support this research was provided by the Krull-Ewing Endowment at Oklahoma State University.

\section{Availability of data and materials}

Data supporting the conclusions of this article are included within the article. The summary datasets used and/or analyzed during the present study are available from the corresponding author upon reasonable request.

Ethics approval and consent to participate Not applicable.

\section{Consent for publication}

Not applicable.

\section{Competing interests}

SL has received honoraria and research support from multiple veterinary pharmaceutical companies that manufacture tick control products. These activities were unrelated to the present study. MS, KS, KD, MI, JJ and PG declare that they have no competing interests.

Received: 6 July 2019 Accepted: 9 December 2019

Published online: 19 December 2019

References

1. Dryden MW, Payne PA. Biology and control of ticks infesting dogs and cats in North America. Vet Ther. 2004;5:139-54.

2. Little SE, Barrett AW, Nagamori Y, Herrin BH, Normile D, Heaney K, et al. Ticks from cats in the United States: patterns of infestation and infection with pathogens. Vet Parasitol. 2018;257:15-20. 
3. Davies S, Abdullah S, Helps C, Tasker S, Newbury H, Wall R. Prevalence of ticks and tick-borne pathogens: Babesia and Borrelia species in ticks infesting cats of Great Britain. Vet Parasitol. 2017;244:129-35.

4. Raghavan M, Glickman N, Moore G, Caldanaro R, Lewis H, Glickman L. Prevalence of and risk factors for canine tick infestation in the United States, 2002-2004. Vector Borne Zoonotic Dis. 2007;7:65-75.

5. Nieto NC, Porter WT, Wachara JC, Lowrey TJ, Martin L, Motyka PJ, et al. Using citizen science to describe the prevalence and distribution of tick bite and exposure to tick-borne diseases in the United States. PLoS One. 2018;13:e0199644.

6. Koch HG. Seasonal incidence and attachment sites of ticks (Acari: Ixodidae) on domestic dogs in southeastern Oklahoma and northwestern Arkansas, USA. J Med Entomol. 1982;19:293-8.

7. Wells AB, Durden LA, Smoyer JH. Ticks (Acari: Ixodidae) Parasitizing domestic dogs in southeastern Georgia. J Entomol Sci. 2004;39:426-32.

8. Thomas JE, Staubus L, Goolsby JL, Reichard MV. Ectoparasites of free roaming domestic cats in the central United States. Vet Parasitol. 2016:228:17-22

9. Burroughs JE, Thomasson JA, Marsella R, Greiner EC, Allan SA. Ticks associated with domestic dogs and cats in Florida, USA. Exp Appl Acarol. 2016;69:87-95.

10. Shannon AB, Rucinsky R, Gaff HD, Brinkerhoff RJ. Borrelia miyamotoi, other vector-borne agents in cat blood and ticks in eastern Maryland. Ecohealth. 2017;14:816-20.

11. Clark KL, Wills W, Tedders SH, Williams DC. Ticks removed from dogs and animal care personnel in Orangeburg County, South Carolina. J Agromed. 1996;3:45-55.

12. Goldberg M, Recha Y, Durden LA. Ticks parasitizing dogs in northwestern Georgia. J Med Entomol. 2002;39:112-4

13. Lavender DR, Oliver JH Jr. Ticks (Acari: Ixodidae) in Bulloch County, Georgia. J Med Entomol. 1996;33:224-31.

14. Rand PW, Lacombe EH, Dearborn R, Cahill B, Elias S, Lubelczyk CB, et al. Passive surveillance in Maine, an area emergent for tick-borne diseases. J Med Entomol. 2007:44:1118-29.

15. Health and Human Services. Report to Congress; 2018. https://www.hhs. gov/sites/default/files/tbdwg-report-to-congress-2018.pdf. Accessed 15 Jan 2019.

16. Show us your ticks. http://www.showusyourticks.org. Accessed 5 Jun 2019.

17. United States Department of Agriculture. Ticks of veterinary importance In: Agriculture handbook No. 485; 1976. https://naldc.nal.usda.gov/downl oad/CAT87208761/PDF. Accessed 1 Feb 2018.

18. Keirans JE, Clifford CM. The genus /xodes in the United States: a scanning electron microscope study and key to the adults. J Med Entomol. 1978;15(Suppl. 2):1-149.

19. Durden LA, Keirans JE. Nymphs of the genus /xodes (Acari: Ixodidae) of the United States: taxonomy, identification key, distribution, hosts, and medical/veterinary importance. Lanham: Entomological Society of America; 1996.

20. Clifford CM, Anastos G, Elbl A. The larval ixodid ticks of the eastern United States (Acarina-Ixodidae). Misc Publ Entomol Soc America. 1961;2:213-37.

21. Keirans JE, Durden LA. Illustrated key to nymphs of the tick genus Amblyomma (Acari: Ixodidae) found in the United States. J Med Entomol. 1998;35:489-95

22. Yunker C, Keirans J, Clifford C, Easton E. Dermacentor ticks (Acari: Ixodoidae: Ixodidae) of the new world: a scanning electron microscope atlas. Proc Entomol Soci Wash. 1986;88:609-27.

23. Brinton EP, Beck DE, Allred DM. Identification of the adults, nymphs and larvae of ticks of the genus Dermacentor Koch (Ixodidae) in the western United States. Brigham Young Univ Sci Bull, Biol Ser. 1965;5:1-44.

24. Macaluso KR, Mulenga A, Simser JA, Azad AF. Differential expression of genes in uninfected and Rickettsia-infected Dermacentor variabilis ticks as assessed by differential-display PCR. Infect Immun. 2003;71:6165-70.

25. Nadolny RM, Wright CL, Hynes WL, Sonenshine DE, Gaff HD. Ixodes affinis (Acari: Ixodidae) in southeastern Virginia and implications for the spread of Borrelia burgdorferi, the agent of Lyme disease. J Vector Ecol. 2011;36:464-7.

26. Ondrejicka DA, Morey KC, Hanner RH. DNA barcodes identify medically important tick species in Canada. Genome. 2017;60:74-84.
27. Dergousoff SJ, Chilton NB. Differentiation of three species of ixodid tick, Dermacentor andersoni, D. variabilis and D. albipictus, by PCRbased approaches using markers in ribosomal DNA. Mol Cell Probes. 2007;21:343-8

28. Trevejo R, Yang M, Lund EM. Epidemiology of surgical castration of dogs and cats in the United States. J Am Vet Med Assoc. 2011;238:898-904.

29. Sonenshine DE. Range expansion of tick disease vectors in North America: implications for spread of tick-borne disease. Int J Environ Res Public Health. 2018;15:E478.

30. White SD, Scott KV, Cheney JM. Otobius megnini infestation in three dogs. Vet Dermatol. 1995:6:33-5.

31. Rich GB. The ear tick, Otobius Megnini (Dugès), (Acarina: Argasidae), and its record in British Columbia. Can J Comp Med Vet Sci. 1957;21:415-8.

32. Beard CB, Occi J, Bonilla DL, Egizi AM, Fonseca DM, Mertins JW, et al. Multistate infestation with the exotic disease-vector tick Haemaphysalis Iongicornis-United States, August 2017-September 2018. MMWR Morb Mortal Wkly Rep. 2018;67:1310-3.

33. Greay TL, Oskam CL, Gofton AW, Rees RL, Ryan UM, Irwin PJ. A survey of ticks (Acari: Ixodidae) of companion animals in Australia. Parasit Vectors. 2016:9:207.

34. I wakami S, Ichikawa Y, Inokuma H. A nationwide survey of ixodid tick species recovered from domestic dogs and cats in Japan in 2011. Ticks Tick Borne Dis. 2014;5:771-9.

35. Shimada Y, Beppu T, Inokuma H, Okuda M, Onishi T. Ixodid tick species recovered from domestic dogs in Japan. Med Vet Entomol. 2003; 17:38-45.

36. Hornok S, Grima A, Takacs N, Kontschan J. Infestation of Rhipicephalus sanguineus sensu lato on cats in Malta. Ticks Tick Borne Dis. 2018;9:1120-4.

37. Duscher GG, Feiler A, Leschnik M, Joachim A. Seasonal and spatial distribution of ixodid tick species feeding on naturally infested dogs from eastern Austria and the influence of acaricides/repellents on these parameters. Parasit Vectors. 2013;6:76.

38. Beck S, Schreibe C, Schein E, Krücken J, Baldermann C, Pachnicke S, et al. Tick infestation and prophylaxis of dogs in northeastern Germany: a prospective study. Ticks Tick Borne Dis. 2014;5:336-42.

39. Maurelli MP, Pepe P, Colombo L, Armstrong R, Battisti E, Morgoglione ME, et al. A national survey of Ixodidae ticks on privately owned dogs in Italy. Parasit Vectors. 2018;11:420.

40. American Pet Products Association's 2017-2018 National Pet Owners Survey. "Facts + statistics: pet statistics." III, 2018, http://www.iii.org/fact-stati stic/facts-statistics-pet-statistics. Accessed 12 May 2019.

41. American Animal Hospital Association. NEWStat. Bayer-American association of feline practitioners study "Why 52 percent of cat owners avoid regular vet visits."; 2013 http://www.aaha.org/blog/NewStat/ post/2013/07/24/437308/Bayer-AAFP-study-explains-why-52-percent-ofcat-owners-avoid-vet-visits.aspx. Accessed 12 May 2019.

42. Cull B, Pietzsch M, Hansford K, Gillingham E, Medlock JM. Surveillance of British ticks: an overview of species records, host associations, and new records of Ixodes ricinus distribution. Ticks Tick Borne Dis. 2018;9:605-14.

43. Geurden T, Becskei C, Six RH, Maeder S, Latrofa MS, Otranto D, et al. Detection of tick-borne pathogens in ticks from dogs and cats in different European countries. Ticks Tick Borne Dis. 2018;9:1431-6.

44. Zhang J, Liu Q, Wang D, Li W, Beugnet F, Zhou J. Epidemiological survey of ticks and tick-borne pathogens in pet dogs in south-eastern China. Parasite. 2017:24:35.

45. Szabó MPJ, de Souza LG, Olegário MM, Ferreira FA, de Albuquerque Pajuaba Neto A. Ticks (Acari: Ixodidae) on dogs from Uberlândia, Minas Gerais, Brazil. Transbounda Emerg Dis. 2010;57:72-4.

46. Pennisi MG, Persichetti MF, Serrano L, Altet L, Reale S, Gulotta L, et al. Ticks and associated pathogens collected from cats in Sicily and Calabria (Italy). Parasit Vectors. 2015;8:512.

\section{Publisher's Note}

Springer Nature remains neutral with regard to jurisdictional claims in published maps and institutional affiliations. 